BNL- 79624 -2007-CP

\title{
End-to-end simulations for the EBIS preinjector
}

\author{
D. Raparia, J. Alessi, A. Kponou, A. Pikin, J. Ritter, \\ BNL, Upton, NY 11973, USA \\ S. Minaev, U. Ratzinger, A. Schempp, R. Tiede, \\ IAP, University of Frankfurt/Main, Germany
}

Presented at the $22^{\text {nd }}$ Particle Accelerator Conference (PAC'07)

Albuquerque, New Mexico

June 25-29, 2007

November 2007

\author{
Collider-Accelerator Department \\ Brookhaven National Laboratory \\ P.O. Box 5000 \\ Upton, NY 11973-5000 \\ www.bnl.gov
}

Notice: This manuscript has been authored by employees of Brookhaven Science Associates, LLC under Contract No. DE-AC02-98CH10886 with the U.S. Department of Energy. The publisher by accepting the manuscript for publication acknowledges that the United States Government retains a non-exclusive, paid-up, irrevocable, world-wide license to publish or reproduce the published form of this manuscript, or allow others to do so, for United States Government purposes. 


\section{DISCLAIMER}

This report was prepared as an account of work sponsored by an agency of the United States Government. Neither the United States Government nor any agency thereof, nor any of their employees, nor any of their contractors, subcontractors, or their employees, makes any warranty, express or implied, or assumes any legal liability or responsibility for the accuracy, completeness, or any third party's use or the results of such use of any information, apparatus, product, or process disclosed, or represents that its use would not infringe privately owned rights. Reference herein to any specific commercial product, process, or service by trade name, trademark, manufacturer, or otherwise, does not necessarily constitute or imply its endorsement, recommendation, or favoring by the United States Government or any agency thereof or its contractors or subcontractors. The views and opinions of authors expressed herein do not necessarily state or reflect those of the United States Government or any agency thereof. 


\title{
END-TO-END SIMULATIONS FOR THE EBIS PREINJECTOR*
}

\author{
D. Raparia ${ }^{\#}$, J. Alessi, A. Kponou, A. Pikin, J. Ritter, BNL, Upton, NY 11973, U.S.A. \\ S. Minaev, U. Ratzinger, A. Schempp, R. Tiede, IAP. University of Frankfurt/Main, Germany
}

\section{Abstract}

The EBIS Project at Brookhaven National Laboratory is in the second year of a four-year project. It will replace the Tandem Van de Graaff accelerators with an Electron Beam Ion Source, an RFQ, and one IH Linac cavity, as the heavy ion preinjector for the Relativistic Heavy Ion Collider (RHIC), and for the NASA Space Radiation Laboratory (NSRL). The preinjector will provide all ions species, $\mathrm{He}$ to $\mathrm{U},(\mathrm{Q} / \mathrm{m}>0.16)$ at $2 \mathrm{MeV} / \mathrm{amu}$ at a repetition rate of $5 \mathrm{~Hz}$, pulse length of $10-40 \mu \mathrm{s}$, and intensities of $\sim 2.0 \mathrm{~mA}$. End-to-end simulations (from EBIS to the Booster injection) as well as error sensitivity studies will be presented and physics issues will be discussed.

\section{INTRODUCTION}

The present pre-injector for heavy ions for the Alternating Gradient Synchrotron (AGS) and Relativistic Heavy ion Collider (RHIC) uses a pair of 33 year old Tandem Van de Graaffs. Many of the Tandem subsystems are becoming obsolete and would have to be replaced to maintain reliable long term operation of RHIC. Other issues with tandems are the stripping foil at the terminal and at high energy lead to intensity and energy variations. Also in tandems ion must start as negative, which results in the limitations on ion species. The 880 meter long doublet transport line to booster makes operation more difficult

The proposed Electron Beam Ion Source (EBIS) based pre-injector is based on modern technologies involving radio frequency quadrupole (RFQ), Inter-digital $\mathrm{H}$ mode drift tube (IH-DTL) linac and only 30 meters long transport line to booster [1]. The new pre-injector makes operation simple and expands the number of ion species available for RHIC or NASA Space Radiation Laboratory (NSRL) program. This pre-injector will inject only 1-4 turns into the booster, as compare to 30-40 from Tandem. The requirement of booster injection for new pre-injector are given in table I.

Table I: Requirement at booster injection for EBIS based pre-injector

\begin{tabular}{|l|l|}
\hline Species & $\mathrm{He}$ to $\mathrm{U}$ \\
\hline Intensity & $\geq 1 \times 10^{11}$ Charges/pulse \\
\hline Charge-to-mass ratio, $\mathrm{Q} / \mathrm{m}$ & $\geq 1 / 6$ \\
\hline Repetition Rate & $5 \mathrm{~Hz}$ \\
\hline Pulse width & $10-40 \mu \mathrm{s}$ \\
\hline Switching time & $1 \mathrm{~s}$ \\
\hline Output energy & $2 \mathrm{MeV} / \mathrm{u}$ \\
\hline Emittance(Nor, full) & $\leq 1.4 \pi \mathrm{mm} \mathrm{mrad}$ \\
\hline Momentum spread, $\Delta \mathrm{P} / \mathrm{P}$ & $\leq \pm 0.05 \%$ \\
\hline
\end{tabular}

*Work supported by the US Department of Energy and the National Aeronautics and Space Administration.

"Raparia@bnl.gov
In comparison to tandem beam, expected transverse and longitudinal emittance will be much higher from the EBIS pre-injector. This feature of EBIS beam demands a very careful choice of design parameters for the pre-injector to control the emittance growth in the both transverse and longitudinal planes.

\section{DESIGN OF THE PRE-INJECTOR}

The proposed EBIS based pre-injector will consist of EBIS itself, low energy beam transport (LEBT), RFQ, medium energy beam transport (MEBT), IH-DTL and high energy beam transport (HEBT). Layout of the preinjector is shown in Figure 1.

In EBIS multi-charged ions are produced in a potential trap inside dense electron beam. Ion injection, confinement, and extraction are fully controllable. The extracted ion beam is formed with ion optics and accelerated to $17 \mathrm{keV} / \mathrm{u}$ in an accelerating tube separating high voltage platform of EBIS and LEBT. EBIS also produces other charge states along with desired charge state, for example if $\mathrm{Au}^{+32}$ is the desired charge state, EBIS will also produce charge states of $30,31,33,34$ in approximately equal amount. To get $\mathrm{Au}^{+32}$ ions of 1.7 emA, EBIS has to produce about $10 \mathrm{emA}$ of current in all charge states. Beam of $10 \mathrm{emA}$ at $17 \mathrm{keV} / \mathrm{amu}$ is space charge dominated. To control the beam in transverse extant, one has to provide transverse focusing more often. We have chosen not to separate charge states until in the HEBT. The LEBT is designed for $10 \mathrm{emA}$ [2].

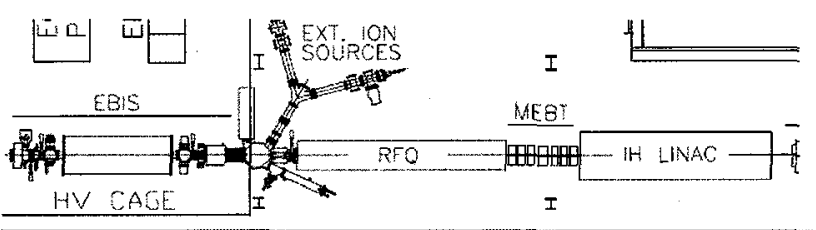

Figure 1: Layout of the EBIS based pre-injector.

At the entrance into LEBT the ion beam can be either focused or defocused (depending on charge to mass ratio and therefore on the accelerating voltage) with a grid lens. The final focusing will be done with a solenoid lens at the entrance into RFQ accelerator. Tuning the Twiss parameters of the ion beam at the entrance into RFQ will be done by adjusting parameters of grid and solenoid lenses. Horizontal and vertical steering of the extracted beam will be done with 2-dimensional 16-pole deflector at the exit from EBIS and sets of parallel plate deflectors in LEBT

The RFQ is being built by the University of Frankfurt group and will be delivered next spring. The detail design of the RFQ is describe in reference 3 . 
The last cell of the RFQ is modified to provide a transverse symmetric beam into the MEBT line. The transmission efficiencies shown in reference 3 are for the desired charge state. In case of gold ion transmission efficiencies of neighboring ions are lower. Simulations show that about $5 \mathrm{emA}$ total beam in all neighboring charge states $(+30,+31,+32,+33,+34)$ will be transmitted by the RFQ. In an RFQ, the longitudinal output emittance decreases as the input current increase. Choice of not to discriminate charges before RFQ provide an extra advantage of getting lower longitudinal emittance out of the RFQ.

We are considering two following options; (A) MEBT with three quadrupoles and buncher in the beginning of the MEBT with total length $64.4 \mathrm{~cm}$. and no change in the phase of last cells in the IH-DTL. (B) MEBT with four quadrupoles and a buncher with total length $81.0 \mathrm{~cm}$. The buncher is located in the middle of the MEBT and the last two cells in the IH-DTL linac will have -90 phase to reduce the momentum spread at the booster entrance. By changing the phase of last two cells the momentum spread at the booster will be reduce at the cost of the little lower $(\sim 40 \mathrm{keV} / \mathrm{u})$ output energy.

Both MEBT configurations should provide enough space for the diagnostics and gate valves for the vacuum separation between RFQ and IH DTL. Here we present only option $\mathrm{B}$, but performance of option $\mathrm{A}$ is similar to option B.

The IH-DTL is also being built by University of Frankfurt group. The IH-DTL is designed with KONUS beam dynamics to accelerate beam to final energies of 2 $\mathrm{MeV} / \mathrm{u}$ for currents up to $10 \mathrm{emA}$. The detail design of the IH-DTL is described in reference 3. The IH-DTL linac will transmit only the nearest charge states. In case of gold ions only $+31,+32$. and +33 will transmitted if the desired charge state is +32 . Simulations show that about 3.2 emA will be transmitted through IH-DTL.

A 30 meters long HEBT consists of seven $20 \mathrm{~cm}$ long quadrupoles, two 73 degree dipoles, two bunchers, beam scrapers at the middle of the two dipoles and diagnostics. The line will join the existing tandem to booster transfer line. The layout of the HEBT is shown in figure 2. Beam will be injected into the booster via existing $17 \mathrm{~mm}$ wide and 2.5 meters long electrostatic inflector with admittance of $29 \mathrm{pi} \mathrm{mm} \mathrm{mrad}$. This is the lowest admittance in the preinjector line. Beam will be matched to the inflector, producing transverse mis-matched beam into the booster. This mismatch will increase the emittance in the booster and will help to reduce space charge tune spread in the booster.

\section{SIMULATIONS}

We start end-to-end simulations from the EBIS. Particle distributions are generated such that ions at a given radius satisfy the transverse velocity due to the space charge potential of electron and ions, and azimuthal velocity due to solenoid field of EBIS. TRAK code was used to track the particles to the entrance of the RFQ

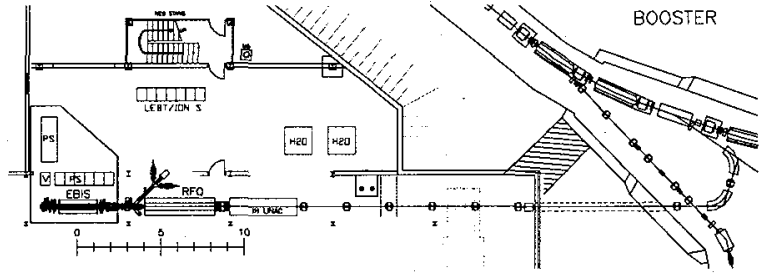

Figure 2: Layout of EBIS based pre-injector, showing injection into Booster.

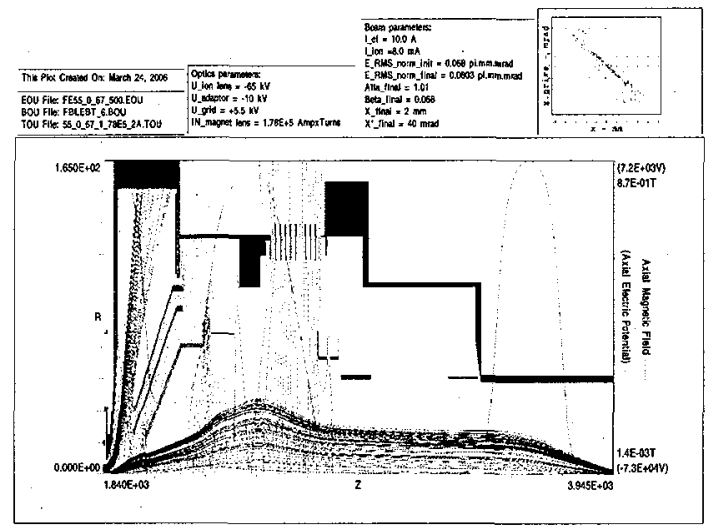

Figure 3: TRAK output for LEBT gold ions.

The output particle distribution from the TRAK code was used as the input distribution for the code PARMTEQM which accelerates particles in the RFQ. PARMILA was used to simulate MEBT. PARMTEQM output particle distributions were used as input to the MEBT. Figure 4 shows the phase space distributions.

The particle distributions through IH-DTL were tracked using code LORASR. The output distribution from the LORASR was used to transport beam to booster entrance using code PARMILA. Figure 5 shows the output distribution at the booster entrance. Figure 6 shows the fraction of the beam vs. $\Delta \mathrm{p} / \mathrm{p}$ on the $\mathrm{x}$-axis.

\section{ERROR SIMULATIONS}

All the errors were divided into two categories; (1) static error, which are independent of time, such as alignment errors, manufacturing defects, etc; (2) dynamic errors, which are time dependent, such as power supply control errors, phase and amplitude errors, etc. A total of 20 sets of errors were generated, i.e. 20 pre-injectors, for design option $\mathrm{B}$. The values for these errors are given in reference 4 . The alignment errors were corrected with the dipole correctors located in the MEBT and HEBT. Only IH-DTL errors were not included because code LORASR is under development to include these errors. Table III summarizes average and $\mathrm{rms}$ values for transmission, emittance, and mis-match factors. 

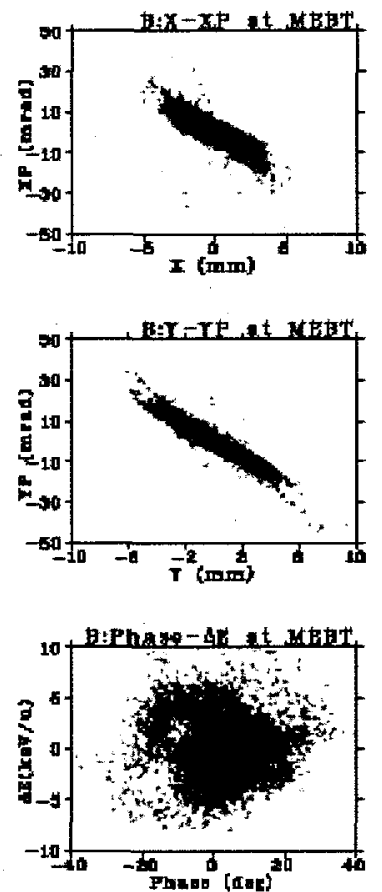

Figure 4: Phase space distribution at end of MEBT.
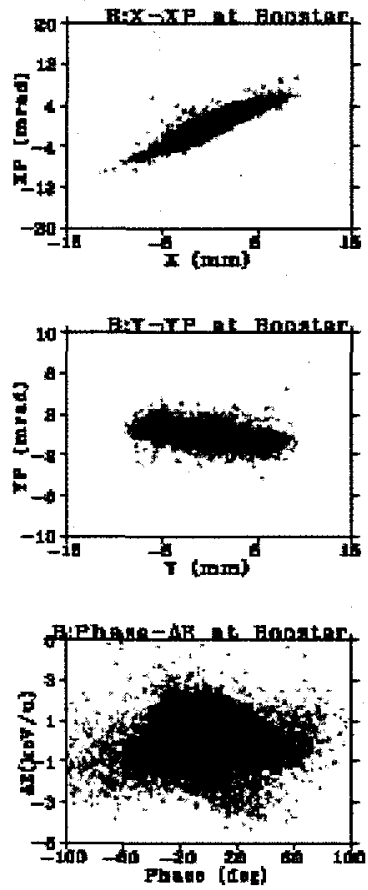

Figure 5: Phase space distribution at the booster.

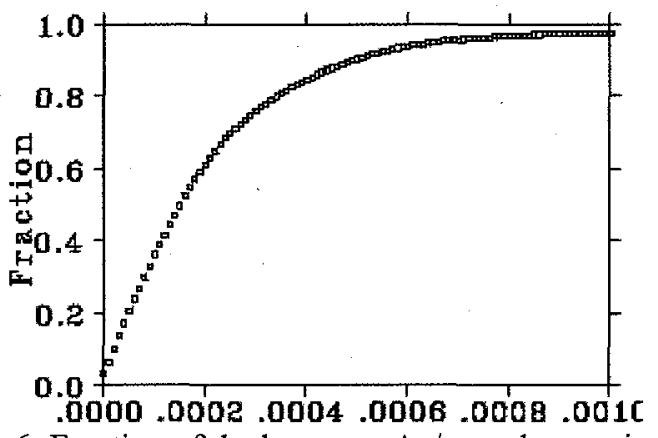

Figure 6: Fraction of the beam vs. $\Delta \mathrm{p} / \mathrm{p}$ on the $\mathrm{x}$-axis.

Table II: RMS emittance and transmission along the preinjector. Transmission is defined with respect to the EBIS Source.

\begin{tabular}{|l|l|l|}
\hline Location & EMIT $(\mathrm{nor}, \mathrm{RMS})$ & \\
\hline RFQ & Ex $(\pi \mathrm{mm} \mathrm{mr})$ & 0.086 \\
\hline & Ey $(\pi \mathrm{mm} \mathrm{mr})$ & 0.092 \\
\hline & Ez $(\pi \mathrm{ns}-\mathrm{keV} / \mathrm{u})$ & 0.0658 \\
\hline & Trans & 0.987 \\
\hline MEBT & Ex $(\pi \mathrm{mm} \mathrm{mr})$ & 0.096 \\
\hline & Ey $(\pi \mathrm{mm} \mathrm{mr})$ & 0.090 \\
\hline & Ez $(\pi \mathrm{ns}-\mathrm{keV} / \mathrm{u})$ & 1.425 \\
\hline & Trans & 0.982 \\
\hline IH-DTL & Ex $(\pi \mathrm{mm} \mathrm{mr})$ & 0.097 \\
\hline & Ey $(\pi \mathrm{mm} \mathrm{mr})$ & 0.096 \\
\hline & Ez $(\pi \mathrm{ns}-\mathrm{keV} / \mathrm{u})$ & 0.579 \\
\hline & Trans. & 0.966 \\
\hline HEBT & Ex $(\pi \mathrm{mm} \mathrm{mr})$ & 0.146 \\
\hline & Ey $(\pi \mathrm{mm} \mathrm{mr})$ & 0.122 \\
\hline & Ez $(\pi \mathrm{ns}-\mathrm{keV} / \mathrm{u})$ & 1.832 \\
\hline & Trans $(\Delta \mathrm{p} / \mathrm{p}=0.1 \%)$ & .960 \\
\hline & Trans $(\Delta \mathrm{p} / \mathrm{p}=0.05 \%)$ & .896 \\
& & \\
\hline
\end{tabular}

Table III: Summary of the error studies. Transmission is defined with respect to the EBIS source and particle which have $\Delta \mathrm{p} / \mathrm{p} \leq 0.05 \%$.

\begin{tabular}{|l|l|l|l|l|}
\hline & Trans & $\begin{array}{l}\text { Ex } \\
(\text { RMS,NOR }) \\
(\pi \mathrm{mm} \mathrm{mr})\end{array}$ & $\begin{array}{l}\text { Ey } \\
(\text { RMS,NOR }) \\
(\pi \mathrm{mm} \mathrm{mr})\end{array}$ & $\begin{array}{l}\text { MMF } \\
(\mathrm{x} / \mathrm{y})\end{array}$ \\
\hline Average & 0.864 & 0.167 & 0.148 & $0.3 / 0.8$ \\
\hline STD & 0.0122 & 0.008 & 0.011 & $0.04 / 0.18$ \\
\hline
\end{tabular}

\section{REFERENCES}

[1] J. Alessi et al., "Status of the EBIS Project at Brookhaven", Proc. of the 2006 LINAC Conf., Knoxville, Tennessee, USA, p.385.

[2] J. Alessi et al., "Design and performance of the matching beamline between the BNL EBIS and an RFQ“, these proceeding.

[3] A. Schempp et al, "RFQ and IH Accelerator for the New EBIS Injector at BNL," these proceeding

[4] D. Raparia, et al., "End-to End simulations for EBIS pre-injector" design note under preparation. 


\title{
END-TO-END SIMULATIONS FOR THE EBIS PREINJECTOR*
}

\author{
D. Raparia ${ }^{\#}$ J. Alessi, A. Kponou, A. Pikin, J. Ritter, BNL, Upton, NY 11973, U.S.A. \\ S. Minaev, U. Ratzinger, A. Schempp, R. Tiede, IAP. University of Frankfurt/Main, Germany
}

\section{Abstract}

The EBIS Project at Brookhaven National Laboratory is in the second year of a four-year project. It will replace the Tandem Van de Graaff accelerators with an Electron Beam Ion Source, an RFQ, and one IH Linac cavity, as the heavy ion preinjector for the Relativistic Heavy Ion Collider (RHIC), and for the NASA Space Radiation Laboratory (NSRL). The preinjector will provide all ions species, $\mathrm{He}$ to $\mathrm{U},(\mathrm{Q} / \mathrm{m}>0.16)$ at $2 \mathrm{MeV} / \mathrm{amu}$ at a repetition rate of $5 \mathrm{~Hz}$, pulse length of $10-40 \mu \mathrm{s}$, and intensities of $\sim 2.0 \mathrm{~mA}$. End-to-end simulations (from EBIS to the Booster injection) as well as error sensitivity studies will be presented and physics issues will be discussed.

\section{INTRODUCTION}

The present pre-injector for heavy ions for the Alternating Gradient Synchrotron (AGS) and Relativistic Heavy ion Collider (RHIC) uses a pair of 33 year old Tandem Van de Graaffs. Many of the Tandem subsystems are becoming obsolete and would have to be replaced to maintain reliable long term operation of RHIC. Other issues with tandems are the stripping foil at the terminal and at high energy lead to intensity and energy variations. Also in tandems ion must start as negative, which results in the limitations on ion species. The 880 meter long doublet transport line to booster makes operation more difficult

The proposed Electron Beam Ion Source (EBIS) based pre-injector is based on modern technologies involving radio frequency quadrupole (RFQ), Inter-digital $\mathrm{H}$ mode drift tube (IH-DTL) linac and only 30 meters long transport line to booster [1]. The new pre-injector makes operation simple and expands the number of ion species available for RHIC or NASA Space Radiation Laboratory (NSRL) program. This pre-injector will inject only 1-4 turns into the booster, as compare to 30-40 from Tandem. The requirement of booster injection for new pre-injector are given in table I.

Table I: Requirement at booster injection for EBIS based pre-injector

\begin{tabular}{|l|l|}
\hline Species & He to U \\
\hline Intensity & $\geq 1 \times 10^{11}$ Charges/pulse \\
\hline Charge-to-mass ratio, Q/m & $\geq 1 / 6$ \\
\hline Repetition Rate & $5 \mathrm{~Hz}$ \\
\hline Pulse width & $10-40 \mu \mathrm{s}$ \\
\hline Switching time & $1 \mathrm{~s}$ \\
\hline Output energy & $2 \mathrm{MeV} / \mathrm{u}$ \\
\hline Emittance(Nor, full) & $\leq 1.4 \pi \mathrm{mm} \mathrm{mrad}$ \\
\hline Momentum spread, $\Delta \mathrm{P} / \mathrm{P}$ & $\leq \pm 0.05 \%$ \\
\hline
\end{tabular}

*Work supported by the US Department of Energy and the National Aeronautics and Space Administration.

"Raparia@bnl.gov
In comparison to tandem beam, expected transverse and longitudinal emittance will be much higher from the EBIS pre-injector. This feature of EBIS beam demands a very. careful choice of design parameters for the pre-injector to control the emittance growth in the both transverse and longitudinal planes.

\section{DESIGN OF THE PRE-INJECTOR}

The proposed EBIS based pre-injector will consist of EBIS itself, low energy beam transport (LEBT), RFQ, medium energy beam transport (MEBT), IH-DTL and high energy beam transport (HEBT). Layout of the preinjector is shown in Figure 1.

In EBIS multi-charged ions are produced in a potential trap inside dense electron beam. Ion injection, confinement, and extraction are fully controllable. The extracted ion beam is formed with ion optics and accelerated to $17 \mathrm{keV} / \mathrm{u}$ in an accelerating tube separating high voltage platform of EBIS and LEBT. EBIS also produces other charge states along with desired charge state, for example if $\mathrm{Au}^{+32}$ is the desired charge state, EBIS will also produce charge states of 30, 31, 33, 34 in approximately equal amount. To get $\mathrm{Au}^{+32}$ ions of 1.7 emA, EBIS has to produce about $10 \mathrm{emA}$ of current in all charge states. Beam of $10 \mathrm{emA}$ at $17 \mathrm{keV} / \mathrm{amu}$ is space charge dominated. To control the beam in transverse extant, one has to provide transverse focusing more often. We have chosen not to separate charge states until in the HEBT. The LEBT is designed for $10 \mathrm{emA}$ [2].

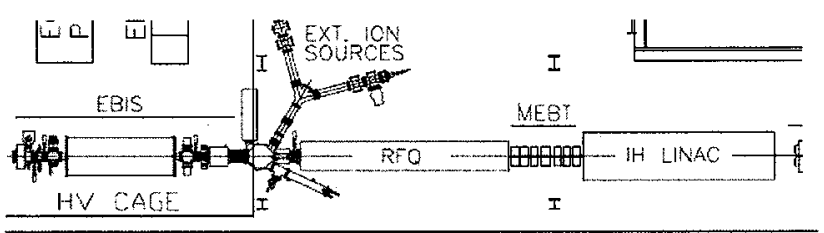

Figure 1: Layout of the EBIS based pre-injector.

At the entrance into LEBT the ion beam can be either focused or defocused (depending on charge to mass ratio and therefore on the accelerating voltage) with a grid lens. The final focusing will be done with a solenoid lens at the entrance into RFQ accelerator. Tuning the Twiss parameters of the ion beam at the entrance into RFQ will be done by adjusting parameters of grid and solenoid lenses. Horizontal and vertical steering of the extracted beam will be done with 2-dimensional 16-pole deflector at the exit from EBIS and sets of parallel plate deflectors in LEBT

The RFQ is being built by the University of Frankfurt group and will be delivered next spring. The detail design of the RFQ is describe in reference 3. 
The last cell of the RFQ is modified to provide a transverse symmetric beam into the MEBT line. The transmission efficiencies shown in reference 3 are for the desired charge state. In case of gold ion transmission efficiencies of neighboring ions are lower. Simulations show that about $5 \mathrm{emA}$ total beam in all neighboring charge states $(+30,+31,+32,+33,+34)$ will be transmitted by the RFQ. In an RFQ, the longitudinal output emittance decreases as the input current increase. Choice of not to discriminate charges before RFQ provide an extra advantage of getting lower longitudinal emittance out of the RFQ.

We are considering two following options; (A) MEBT with three quadrupoles and buncher in the beginning of the MEBT with total length $64.4 \mathrm{~cm}$. and no change in the phase of last cells in the IH-DTL. (B) MEBT with four quadrupoles and a buncher with total length $81.0 \mathrm{~cm}$. The buncher is located in the middle of the MEBT and the last two cells in the IH-DTL linac will have -90 phase to reduce the momentum spread at the booster entrance. By changing the phase of last two cells the momentum spread at the booster will be reduce at the cost of the little lower $(\sim 40 \mathrm{keV} / \mathrm{u})$ output energy.

Both MEBT configurations should provide enough space for the diagnostics and gate valves for the vacuum separation between RFQ and IH DTL. Here we present only option $\mathrm{B}$, but performance of option $\mathrm{A}$ is similar to option B.

The IH-DTL is also being built by University of Frankfurt group. The IH-DTL is designed with KONUS beam dynamics to accelerate beam to final energies of 2 $\mathrm{MeV} / \mathrm{u}$ for currents up to $10 \mathrm{emA}$. The detail design of the IH-DTL is described in reference 3. The IH-DTL linac will transmit only the nearest charge states. In case of gold ions only $+31,+32$. and +33 will transmitted if the desired charge state is +32 . Simulations show that about $3.2 \mathrm{emA}$ will be transmitted through IH-DTL.

A 30 meters long HEBT consists of seven $20 \mathrm{~cm}$ long quadrupoles, two 73 degree dipoles, two bunchers, beam scrapers at the middle of the two dipoles and diagnostics. The line will join the existing tandem to booster transfer line. The layout of the HEBT is shown in figure 2. Beam will be injected into the booster via existing $17 \mathrm{~mm}$ wide and 2.5 meters long electrostatic inflector with admittance of $29 \mathrm{pi} \mathrm{mm} \mathrm{mrad}$. This is the lowest admittance in the preinjector line. Beam will be matched to the inflector, producing transverse mis-matched beam into the booster. This mismatch will increase the emittance in the booster and will help to reduce space charge tune spread in the booster.

\section{SIMULATIONS}

We start end-to-end simulations from the EBIS. Particle distributions are generated such that ions at a given radius satisfy the transverse velocity due to the space charge potential of electron and ions, and azimuthal velocity due to solenoid field of EBIS. TRAK code was used to track the particles to the entrance of the RFQ

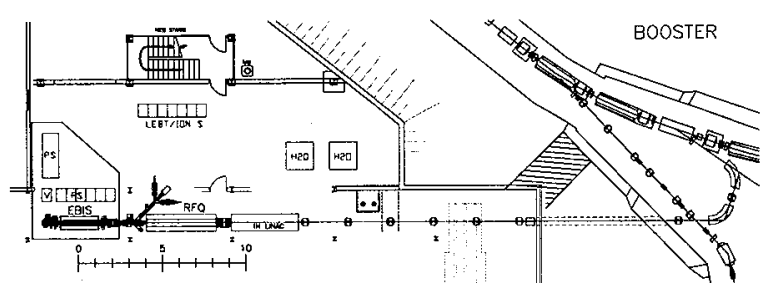

Figure 2: Layout of EBIS based pre-injector, showing injection into Booster.

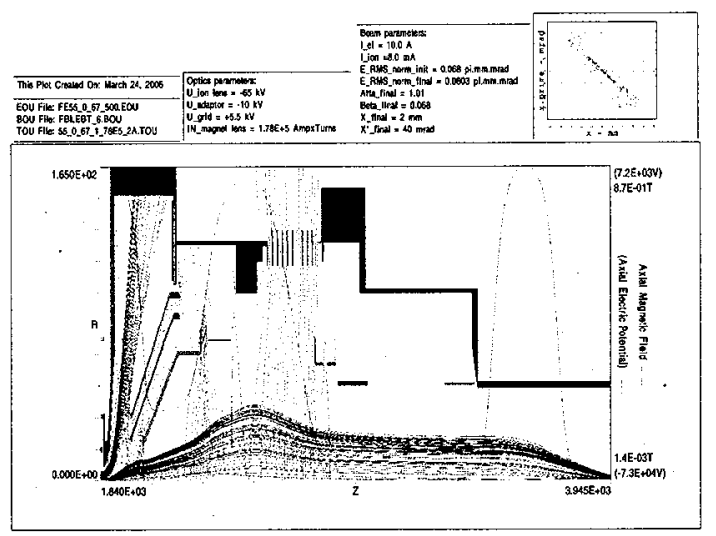

Figure 3: TRAK output for LEBT gold ions.

The output particle distribution from the TRAK code was used as the input distribution for the code PARMTEQM which accelerates particles in the RFQ. PARMILA was used to simulate MEBT. PARMTEQM output particle distributions were used as input to the MEBT. Figure 4 shows the phase space distributions.

The particle distributions through IH-DTL were tracked using code LORASR. The output distribution from the LORASR was used to transport beam to booster entrance using code PARMILA. .Figure 5 shows the output distribution at the booster entrance. Figure 6 shows the fraction of the beam vs. $\Delta \mathrm{p} / \mathrm{p}$ on the $\mathrm{x}$-axis.

\section{ERROR SIMULATIONS}

All the errors were divided into two categories; (1) static error, which are independent of time, such as alignment errors, manufacturing defects, etc; (2) dynamic errors, which are time dependent, such as power supply control errors, phase and amplitude errors, etc. A total of 20 sets of errors were generated, i.e. 20 pre-injectors, for design option $B$. The values for these errors are given in reference 4 . The alignment errors were corrected with the dipole correctors located in the MEBT and HEBT. Only IH-DTL errors were not included because code LORASR is under development to include these errors. Table III summarizes average and rms values for transmission, emittance, and mis-match factors. 

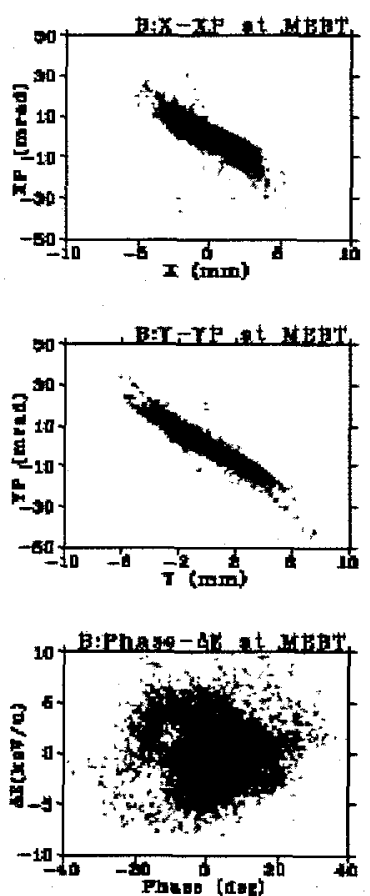

Figure 4: Phase space distribution at end of MEBT.
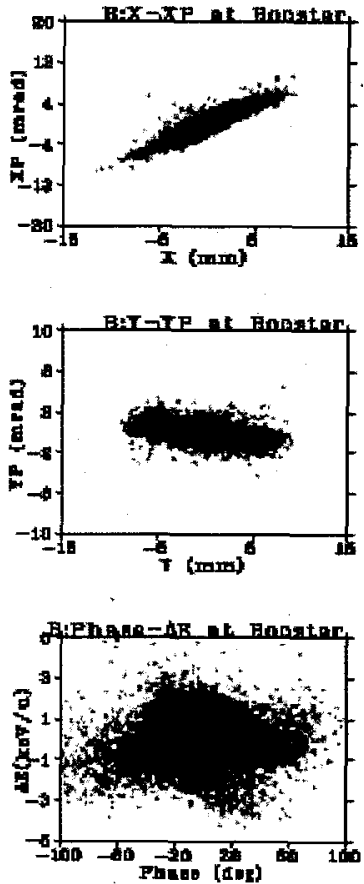

Figure 5: Phase space distribution at the booster.

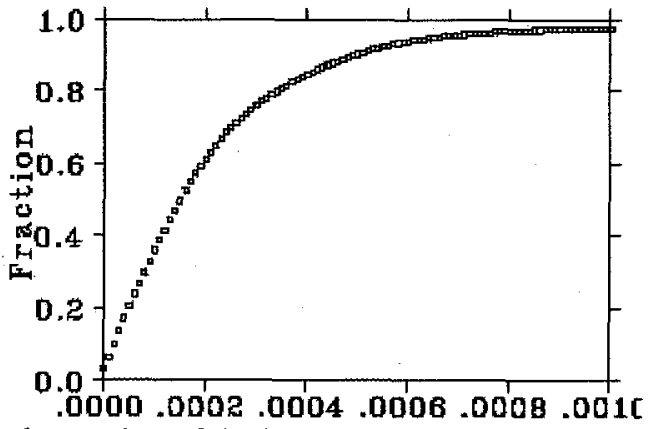

Figure 6: Fraction of the beam vs. $\Delta \mathrm{p} / \mathrm{p}$ on the $\mathrm{x}$-axis.

Table II: RMS emittance and transmission along the preinjector. Transmission is defined with respect to the EBIS Source.

\begin{tabular}{|l|l|l|}
\hline Location & EMIT (nor, RMS) & \\
\hline RFQ & Ex $(\pi \mathrm{mm} \mathrm{mr})$ & 0.086 \\
\hline & Ey $(\pi \mathrm{mm} \mathrm{mr})$ & 0.092 \\
\hline & Ez $(\pi \mathrm{ns}-\mathrm{keV} / \mathrm{u})$ & 0.0658 \\
\hline & Trans & 0.987 \\
\hline MEBT & Ex $(\pi \mathrm{mm} \mathrm{mr})$ & 0.096 \\
\hline & Ey $(\pi \mathrm{mm} \mathrm{mr})$ & 0.090 \\
\hline & Ez $(\pi \mathrm{ns}-\mathrm{keV} / \mathrm{u})$ & 1.425 \\
\hline & Trans & 0.982 \\
\hline IH-DTL & Ex $(\pi \mathrm{mm} \mathrm{mr})$ & 0.097 \\
\hline & Ey $(\pi \mathrm{mm} \mathrm{mr})$ & 0.096 \\
\hline & Ez $(\pi \mathrm{ns}-\mathrm{keV} / \mathrm{u})$ & 0.579 \\
\hline & Trans. & 0.966 \\
\hline HEBT & Ex $(\pi \mathrm{mm} \mathrm{mr})$ & 0.146 \\
\hline & Ey $(\pi \mathrm{mm} \mathrm{mr})$ & 0.122 \\
\hline & Ez $(\pi \mathrm{ns}-\mathrm{keV} / \mathrm{u})$ & 1.832 \\
\hline & Trans $(\Delta \mathrm{p} / \mathrm{p}=0.1 \%)$ & .960 \\
\hline & Trans $(\Delta \mathrm{p} / \mathrm{p}=0.05 \%)$ & .896 \\
& & \\
\hline
\end{tabular}

Table III: Summary of the error studies. Transmission is defined with respect to the EBIS source and particle which have $\Delta \mathrm{p} / \mathrm{p} \leq 0.05 \%$.

\begin{tabular}{|l|l|l|l|l|}
\hline & Trans & $\begin{array}{l}\text { Ex } \\
(\text { RMS,NOR }) \\
(\pi \mathrm{mm} \mathrm{mr})\end{array}$ & $\begin{array}{l}\text { Ey } \\
(\text { RMS,NOR }) \\
(\pi \mathrm{mm} \mathrm{mr})\end{array}$ & $\begin{array}{l}\text { MMF } \\
(\mathrm{x} / \mathrm{y})\end{array}$ \\
\hline Average & 0.864 & 0.167 & 0.148 & $0.3 / 0.8$ \\
\hline STD & 0.0122 & 0.008 & 0.011 & $0.04 / 0.18$ \\
\hline
\end{tabular}

\section{REFERENCES}

[1] J. Alessi et al., "Status of the EBIS Project at Brookhaven", Proc. of the 2006 LINAC Conf., Knoxville, Tennessee, USA, p.385.

[2] J. Alessi et al., "Design and performance of the matching beamline between the BNL EBIS and an RFQ", these proceeding.

[3] A. Schempp et al, "RFQ and IH Accelerator for the New EBIS Injector at BNL," these proceeding

[4] D. Raparia, et al., "End-to End simulations for EBIS pre-injector" design note under preparation. 